\title{
SSL technology development and commercialization in the global context
}

\author{
Kenneth L. Simons ${ }^{\mathrm{a}}$ and Susan Walsh Sanderson ${ }^{\mathrm{a}}$ \\ ${ }^{\text {a }}$ Rensselaer Polytechnic Institute, $1108^{\text {th }}$ Street, Troy, NY USA 12180
}

\begin{abstract}
Multi-national patents and applications data, based on filings in patent authorities worldwide, are used as a means to probe corporate and national R\&D roles in the emerging LED and SSL industries. The data are counts of patents, applications, or applications filed in at least two patent authorities, and do not have means to control for the importance of individual patents. Nonetheless they provide a helpful way to assess the companies and nations involved in LED and SSL research in general and in specific technological sub-domains. Some of the leading companies and nations are reported on. The data show Samsung's rapid rise to prominence in these technologies. They indicate a greater role of nations other than the U.S. than has been noted in previous patent analyses, since the tendency of applicants to file predominantly in their home countries has meant that counts based solely on U.S. patents have missed large numbers of non-U.S. applicants active in this technology while still counting U.S. applicants that filed solely in the U.S. They reveal growing activity in Asia, partly in Korea because of Samsung's role, and partly in Taiwan and mainland China.
\end{abstract}

Keywords: solid state lighting, light emitting diodes, research and development, patents, companies, national innovation, benchmarks, international patent families, patent applications, utility models

\section{INTRODUCTION}

Advances in solid state lighting (SSL) technologies have the potential to have a significant impact on energy conservation and global warming as well as providing the foundation for several $21^{\text {st }}$ century industries. But the determinants of successful commercialization and diffusion of SSL, as well as other energy saving technologies are not well understood, particularly in a global context.

Missing from our national debate is an understanding of differences between the U.S., Japan, Germany, the Netherlands, South Korea, Taiwan, and China, nations all poised to play a key role in the future of SSL. The global context is crucial, because producers worldwide are competing to play a role in developing, manufacturing, and marketing solid state lighting technologies and products, with some nations promoting rapid development and adoption.

This study assesses global technology patterns and trends by measuring SSL related patents. SSL patenting worldwide is considered for all nations in which relevant patent data can be obtained.

Business and research organizations in the U.S. are compared to their foreign counterparts, and patents applied for or granted in the U.S. (at the U.S. Patent and Trademark Office) are compared to patents applied for or granted in nearly 70 other nations (at their respective patent office). This includes all nations in which substantial SSL, and light emitting diode (LED) and organic light emitting diode (OLED), activity seems to be occurring, including the United States, Japan, Taiwan, South Korea, and China.

Specifically, the study has focused on:

- Comparison of SSL corporate activity, showing leading firms worldwide with the activity of each plotted over time.

- International comparison of locations of SSL inventive activity, showing SSL patent invention activity by nation and time.

- International comparison of SSL patent granting (and where possible SSL patent application) activity, showing SSL activity over time, across patent authorities in different nations for which there is substantial SSL patenting.

- Locations of R\&D activities of key firms, using non-patent information sources to confirm and give context to the patent findings. 
These topics are addressed here for all types of SSL and LED (including OLED) technologies, and for certain specific technologies of interest.

The diffusion of new SSL technologies is affecting several industry sectors - from traffic and architectural lighting to stationary and mobile displays used in computers, TVs, and mobile devices. The market is driven by technology and product development advances and also by buyers who want products with greater functionality, styling, and energy savings.

Solid-state lighting has become a national priority for many of the world's nations. In addition to their motivation to save, many governments see it an important generator of employment and wealth creation. Substantial SSL/LED research and development has been ongoing in the United States, Japan, Korea, Taiwan, Germany and the Netherlands.

The national priority programs for SSL in Taiwan and China should come as no surprise. Not only does SSL promise energy efficiency that the developing Asian economy desperately needs; it also coincides with economic opportunity. Taiwan seeks to solidify its position as the leader in manufacture of LEDs and other solid-state components, and to continue to expand its role in related product design and development. China seeks to be a player in nascent SSL manufacturing and according to official figures has been pouring over a billion dollars into pertinent industrial parks; at the same time SSL has been one of the research priorities of the Chinese Academy of Sciences.

International competition to develop this strategically important industry raises issues for U.S. policy. This report contributes to our understanding of these important emerging technologies in the context of the key firms and regions that are contributing significantly to its development. According to our analysis and people knowledgeable about the early development of SSL, Asia has historically been the epicenter for the development of chips, is strong in packaged LED lamps, and was responsible for the earliest mainstream applications, including keypads, handhelds, and display backlighting. Europe has been forward thinking in lighting design, responsible for early automotive applications, and an early champion of OLED technologies. The U.S. and Canada have focused to some degree on intellectual property involved in today's light engines and control systems.

There is already a clustering of activities in the value chain across different regions of the world that have built on earlier investments in foundational materials, processes, and technologies. Moreover, a host of global players, large and small, draw on global supply chains in developing, designing, and assembling final products. Large global firms such as Philips, Siemens (including OSRAM Sylvania), and GE have operations around the world that are focused on research, design, and assembly. Even startup firms, like Color Kinetics (recently purchased by Philips) were born global, buying devices and assembling their architectural lighting products in Taiwan and the Chinese mainland.

\section{DATASET CONSTRUCTION}

To document and analyze SSL R\&D, a systematic source of evidence is needed. This evidence must span the range of people, companies, institutions, and nations involved in SSL, and provide at least an indicator of their involvement in relevant $R \& D$. Two types of evidence are available fairly consistently across the players in SSL R\&D: publications and patents. Of the two, publications are a better measure of basic R\&D and tend to come from the university sector, whereas patents are a better measure of applied $R \& D$ and tend to come from businesses. Patents are therefore the focus of this study. Patents granted from patent authorities worldwide are considered, to avoid potential U.S.-centric biases that might result when examining data only on U.S. patents. Patents stem from applications, which provide leading-edge evidence on R\&D activity, and hence applications data are used here to gain understand of the most recent trends. Patents' poor cousins, utility models, are granted by many nations (not the U.S.) for typically six years' rights with a much-simplified application process, and data on granted utility models are included to provide further evidence on R\&D activity for which less formal protection is sought. All this evidence had to be built up in a systematic database.

\subsection{Primary data source}

We began with data from the European Patent Office's (EPO's) "EPO Worldwide Patent Statistical Database." The EPO collects patent data from national patent offices worldwide and places it on its esp@cenet Internet search system, which is publicly accessible on the Internet. The Worldwide Patent Statistical Database consists of bibliographic data drawn fromesp@cenet, along with data on some types of publications not shown in esp@cenet, for all patent authorities and time periods in which data are available. The data include, ideally, the numbers, titles, abstracts, technology classifications (national and international), applicant names, inventor names, citations, and various types of publications for each patent or utility model applied for. In practice, such data are a recent creation, so the availability of abstracts, 
citation data, title translations, and other desirable features varies across national patent offices and time. Missing data are common even for the United States Patent and Trademark Office, for which for example citations data are available only sporadically in many years including recent years. Hence abstracts and citations data, which are rarely available in the full dataset, are not exploited here. The data identify one or more publications for each patent or utility model application, using a series of nation- and time-specific codes for the type of publication. After combing through these codes, we ruled out applications that only had publications indicating translation of another patent office's documents. We also categorized codes that indicate an application was granted as a patent or as a utility model. The data cover about ninety nations' patent authorities worldwide, including all of the nations most active in LED R\&D and patenting (such as the U.S., Canada, the European Community plus individual European nations, Japan, Korea, Taiwan, China, and Australia). These individual patent authorities continually supply information to the EPO, which puts the data into useable form and loads it into esp@cenet, then carries out several more cleaning steps

\subsection{Search strategy}

Within the EPO dataset, we identified relevant patents based on both application titles and international patent classification (IPC) codes. Titles in the EPO dataset mainly have been translated to English language, but a fraction of European-language titles remain in their original European languages. When we searched titles we therefore focused our efforts on English-language searches, but we used rudimentary non-English-language keywords and international patent classification codes to identify relevant applications that had non-English language title data. A small percentage of applications in the data have no title data available, and a small percentage have no IPC code data available. Searching by both methods allowed us to identify relevant applications that lacked one of these types of data in the EPO Worldwide Patent Statistical Database.

Title search strings were identified through a succession of investigations of likely terms to identify LED- and SSLrelated applications. We also identified relevant search strings by examining all applications by LED-related firms, that is, firms whose activity has been focused narrowly on LED- (and SSL-) related applications. These firms included Cree, Color Kinetics (now Philips Color Kinetics), and Nichia. We also investigated possible terms by checking titles of patents designated in U.S. class 362/800, the U.S. Patent and Trademark Office's light-emitting diode cross-reference art collection. Applications that matched any one or more of our title keyword strings or IPC codes were included in the database.

Search results were checked to ensure that they did not erroneously identify any substantial percentage of off-topic applications. One of our title search terms, "LED", did yield a small percentage of off-topic applications, because titles might use the verb "led" for example for a pipe "led through" a cylinder wall or a wire "led into" a circuit. Therefore for "LED" only we examined all titles that used this word to ensure that they were not misuses of the word "led", and we removed from the data these irrelevant applications.

Title searches required whole words to be identified (separated by spaces or non-alphanumeric characters such as punctuation marks). An "(s)" or "(n)" denotes an optional s or n, and an asterisk allows any characters. Searches were not case-sensitive.

The following English-language keyword strings were used to search titles: "light emitting diode(s)", "light-emitting diode(s)", "LED(s)", "OLED(s)", "PLED(s)", "L.E.D.(s)", "LED based", "LED-based", "semiconductor light emitting", "semiconductor light-emitting", "semiconductor light emission", "semiconductor lighting", "semiconductor lumin*", "solid state lighting", "solid-state lighting", "solid state light(s)", "solid-state light(s)", "solid state lamp(s)", "solid-state lamp(s)", "micro-LED(s)", "light emitting die(s)", "light-emitting die(s)", "luminescent diode(s)", "light emittingdiode(s)", "lightemitting diode(s)", "lightemittingdiode(s)".

The following basic non-English-language keyword strings were used to search titles: "lichtemittierende Diode(n)", "Leuchtdiode(n)", "diode(s) luminescente(s)", "diodo(s) electroluminoso(s)", "diodo(s) luminoso(s)", "diodo luminescente", "diodi luminescenti", "luminescente diodo", "luminescenti diodi", "diodos emissores de luz", "diodo(s) emitindo-se claro(s)". These non-English language search terms covered the non-English languages in which there are, with any substantial frequency, non-English titles in the EPO dataset. Asian titles never appear in the EPO dataset; all titles for patents originating in Asian patent offices have either been translated to English or (generally for some quite old applications) lack title data in the EPO dataset. 
Table 1. International patent classifications searched for with frequencies and descriptions

\begin{tabular}{lcl}
\hline Category & $\begin{array}{c}\text { Number of } \\
\text { applications }\end{array}$ & Brief informal description \\
\hline H01L33/00 & 79,672 & $\begin{array}{c}\text { Semiconductor devices for light emission, including manufacture and details } \\
\text { thereof }\end{array}$ \\
H05B33 & 63,003 & Lighting - Electroluminescent light sources \\
G09G3/30 & 14,977 & Circuits for readable displays using electroluminescent panels \\
G09G3/32 & 9,861 & As G09G3/30, using semiconductors \\
G09F9/33 & 8,718 & Pixel-based displays using semiconductors \\
H01L27/15 & 6,233 & Solid-state circuitry incorporating semiconductor light-emitting devices \\
G09G3/14 & 2,738 & As G09G3/32, but for displaying a single character \\
\hline
\end{tabular}

Table 2. Percentage of applications in various groups caught by search

\begin{tabular}{lcc}
\hline Group of applications & Number of applications & Percent caught by search \\
\hline Filed by Color Kinetics & 272 & $49.6 \%$ \\
Filed by Cree & 1885 & $41.3 \%$ \\
Filed by Nichia & 3373 & $58.1 \%$ \\
U.S. class 362/800 & 1775 & $44.8 \%$ \\
\hline
\end{tabular}

We also included applications that were classified in any of several IPC code categories. Codes used were chosen to be narrowly focused on LEDs or semiconductor electroluminescence. The codes searched for use (almost entirely) the 2006.01 advanced version of the international patent classification system. The codes searched for, in order of frequency of occurrence, are: H01L33/00, H05B33 (all subgroups), G09G3/30, G09G3/32, G09F9/33, H01L27/15, and G09G3/14. This would catch some applications related to lasers, so we partially screened out applications most directly related to lasers by ignoring resulting applications that include "laser(s)" in their titles, unless those applications were also identified based on title searches. The number of applications (granted or not, for patents or utility models) classified as having each of these codes is listed in Table 1. Some applications had more than one of these codes, since the average application in our data had 3.6 IPC codes.

This approach does not identify all LED- or SSL-related applications, but does identify a large percentage. Applications whose titles and classification codes do not satisfy the search methods used here could still be applicable in various ways to LEDs or SSL. To better understand the frequency with which relevant applications were caught by the search procedures used here, we analyzed all applications filed by several firms that specialize in aspects of SSL (Cree, Color, as well as all applications catalogued in U.S. class 362/800, the light-emitting diode cross-reference art collection, as of the most recent available EPO data at the time of this study. Table 2 shows the result of this check. Approximately half of all relevant patents seem to be identified by the search methods used, with some variations in this fraction between different companies, nations, and types of information sources. This substantial fraction, and its comparable size across the groups, is reassuring that meaningful analyses can be carried out using the dataset developed here.

\subsection{Nationality data and sampling procedures}

When analyzing inventors' nations of residence, as well as applicants' nations of address, the EPO Worldwide Patent Statistical Database causes two problems. First, the data contain frequent gaps in available data on the nations of residence of inventors. These gaps are most frequent for particular national patent offices and particular nations of residence, and differ in frequency by time period, patent versus utility model applications, and granted versus nongranted applications. As a result, ignoring the gaps and calculating results based on available data would yield biased findings. For example, the inventor nation is often missing for patent applications with Japanese inventors. If one blindly computed the percentage of patents with Japanese inventors based on available data, the answer would be erroneously low, suggesting that Japanese inventors played a much more minor role than their real percentage of contributions to applications.

Second, mainland China and Taiwan often are coded identically. If this problem were not noticed, an analyst attempting to tell apart mainland China and Taiwan might conclude that mainland China's role in SSL R\&D is substantially greater 
than its actual role. The issue arises frequently for applications filed with the State Intellectual Property Office of the People's Republic of China, but also arises sometimes for applications filed in other nations.

To deal with these problems, we looked up and compiled by hand the nationality data for a sample of applications with missing inventor locations and a sample of applications in which the location was recorded as China. The modern survey research methods that we used involved subdividing the patent data into "strata" (by language, technology classes, whether patents were granted, etc.) and collecting data on randomly-selected applications in each stratum. Statistical methods designed for surveys were applied to the resulting data to understand the range of error in our findings; in all cases the resulting range of error was small. To collect the data, our team of research assistants looked up facsimile images of published documents and read the inventor nations from these documents. Since these documents were published in Japanese, Chinese, Korean, and various European languages, the team was chosen to include persons fluent in many languages. We were unable to obtain a research assistant fluent in Cyrillic languages, leading to some undercounting of applications filed in Russia and nearby nations, probably most frequently by inventors in those nations. Data entry was double-checked for some of the research assistants collect data for the same applications twice; the error rate in these cases was minimal. Given the considerable expense and effort required, we reduced costs by not looking up the nations of applicants when data were missing, but only of inventors, and then assuming that the distribution of nations in the two cases of missing information was the same - a seemingly reasonable assumption judging from initial investigations on a subset of the data.

Nationality data were compiled in this way only up to the previous ("September 2008") edition of the EPO data, since the subsequent edition was finished by the EPO only in June 2009 shortly before this report was completed. Hence analyses of nationality data here exclude the most recent six months of information that is included in analyses by company and other analyses.

By far the largest number of applications in the data, and by far the largest number for which inventor locations were missing, was for applications filed with the Japan Patent Office. To reduce the data collection effort, we obtained massive data files in Japanese language regarding nearly all applications filed with the Japan Patent Office (JPO) over an extended period. The data do not match readily to the EPO data, but Dr. Jun Suzuki of the Graduate Institute for Policy Studies in Tokyo kindly created a matching table that allowed us to match between the two datasets. This allowed us to match many of our Japanese language applications to the JPO data. The data include the addresses of inventors in Japanese language, and we programmatically extracted the nation names from these addresses. Our algorithm worked very effectively as judged by applicant nation data available from the JPO, since our conclusions almost always agreed and in the few cases of differences our algorithm much more often (and statistically significantly) outperformed the JPO classification assuming the JPO's address data are correct. When all inventors were from the same nation (which is almost always true), we used this information to determine the nation of residence of all inventors. This matching and nation determination procedure provided nation of inventor residence information for approximately half of all Japanese applications with missing inventor locations, substantially reducing the data collection challenge.

Among 47,839 applications with missing inventor locations, we collected information on 9,804 applications. Among 7,424 applications with inventor locations denoted as China, we collected information on 5,278 applications. This gives quite small margins of error for nations with substantial numbers of patents, granted applications, or applications respectively.

\subsection{Identification of technology sub-domains}

We classified each application in our data into zero or more technology sub-domains. Our classification of technology types is based on both international patent classification (IPC) codes assigned to each application, and the title of each application. A minority of applications have no IPC data or no title data, though all have at least one of the two, and in these cases we used the available title or IPC data to classify them as usual, albeit with less opportunity for classification into any given category.

Our overall category, All, includes all applications in the data. If one wishes to focus on general illumination applications, it helps to filter out the most frequently occurring other technologies involving LEDs: displays, printers, and scanners. Categories created for Displays and (not used here) Printers \& Scanners identify applications involving these technologies. Removing display, printer, and scanner related applications from All yields the category All But Displays, Printers, and Scanners. This category includes LEDs and related materials, circuitry, and manufacture as well 
as the use of LEDs in myriad applications. Indicator lights and some unusual applications remain. Unfortunately there is no easy way to classify applications according to the color or intensity of light emitted.

Fundamental technologies including LED design, materials, packaging, methods of manufacture, and control circuitry make up a large part of the data. To attempt to systematize analysis of these fundamental technologies, rather than applications, we therefore created a Fundamental category based on a broad range of IPC codes.

A purist might attempt to focus on applied general illumination lighting technologies by removing from consideration any application that in any way is not lighting, including fundamental technologies. This reductionist applied focus yields a category denoted Lighting, with very small numbers of applications, but largely free of contamination from other sorts of technology. This category may be useful to get an idea of the locus of innovative activity in applied general illumination lighting.

Two further categories are used here. Organic consists of applications involving organic chemicals, and Vehicle consists of applications explicitly relevant to vehicles.

Table 3 lists the categories along with their formal definitions. The definitions rely on IPC- and title- based classifications reported in Tables 4 and 5 respectively. Applications matching any item in a list of IPC codes or title keywords are included. Title searches were not whole-word searches (in contrast to title searches used to identify the overall dataset) and were not case-sensitive. Some title search strings included spaces or the carat $\left({ }^{\wedge}\right)$ marker which indicates that the string must appear at the start of the title. For the category Organic, we follow the practice of Boyack et al. (2006) of excluding applications that include the title term "metal organic", a minority of which pertain to chemical vapor deposition equipment. ${ }^{[1]}$

\subsection{Other aspects of data preparation}

Other data analysis work necessary included matching of alternate, misspelled, and changed company names; determination of company ownership and acquisition; codification of types of documents published by patent offices; development of 10,000 lines of complex data programming code; and creation of thorough programmatic checks to ensure correct treatment of the data.

\section{FEATURES OF THE PATENT DATABASE}

The dataset consists of 185,852 applications filed in 68 nations. The earliest SSL or LED related applications appear to have been filed by the mid-1930s, and the latest on the fourth day of December, 2008. The most recently granted patent in the data was granted on the fifth day of March, 2009 (it was applied for on April 12, 2002 in Germany). There are 59,633 granted patents. The data also cover 12,499 granted utility models and (in a few cases) other receipts such as communist-style inventor's certificates. As noted below, actual counts used hereafter are lower than these numbers,

Table 3. Technology category definitions

\begin{tabular}{|c|c|}
\hline Category & Definition (subset of dataset) \\
\hline All & All applications \\
\hline $\begin{array}{l}\text { All but displays, printers, } \\
\text { and scanners }\end{array}$ & $\begin{array}{l}\text { Any application not in any of the IPC categories: Display Projector PrintScan } \\
\text { PhotoPrinter FundSemiPl, and not in any of the title categories: DispPrintScan } \\
\text { Backlight }\end{array}$ \\
\hline Lighting & $\begin{array}{l}\text { Any application in the overall category All But Displays, Printers, and Scanners, that } \\
\text { is also in IPC category: Lighting or in any of the title categories: Lamp } \\
\text { WhiteLight, but only if it is not in title category Indicator and not in overall } \\
\text { category Fundamental }\end{array}$ \\
\hline Fundamental & $\begin{array}{l}\text { Any application in any of IPC categories: FundOptics FundElectr FundSemic } \\
\text { FundComm FundManuf FundChem }\end{array}$ \\
\hline Displays & $\begin{array}{l}\text { Any application in any of the IPC categories: Display Projector FundSemiPl, or in } \\
\text { title category: Display }\end{array}$ \\
\hline Organic & $\begin{array}{l}\text { Any application in IPC category Organic or in title category Organic, but not in title } \\
\text { category MetalOrganic }\end{array}$ \\
\hline Vehicle & Any application in IPC category: Vehicle \\
\hline
\end{tabular}


Table 4. IPC-based categories used in technology category definitions

\begin{tabular}{ll}
\hline Category & Definition (IPCs included) and comments \\
\hline Lighting & E01C17 E01F13 E01F9 F21 G08G G09F13 H05B31-43 [Primary lighting applications.] \\
Display & G09G3/03-38 G09F9 H04N3-17 G09G5 G04G9 G06F3/147 G06F3/033 \\
Projector & G02B27/18 G03B21 H04N5/74 H04N9/31 \\
PrintScan & B41J G03G15 G06K15 H04N1 B41 G06K7 [Printing and some scanning uses of \\
& LEDs/OLEDs/PLEDs.] \\
PhotoPrinter & G03B27 \\
Vehicle & B60-64 \\
FundOptics & G02B G02F \\
FundElectr & H01J H01R H01S H03K H05K \\
FundSemic & H01L21 H01L23 H01L25 H01L29 H01L31 H01L51 G03F G11C, also H01L33/00 if that is the \\
& only IPC listed on the patent [Classify based on H01L33/00 only if it is the sole IPC for an \\
application because many applications list this simply to indicate an LED is involved.] & \\
FundSemiP1 & H01L27 [Fundamentals of semiconductors for devices with a plurality of components, most of \\
& which pertain to displays and arrays, which are rarely pertinent to present-day general \\
FundComm & H04B10 H04M H04Q [Communications including telephonic and light-beam.] \\
FundManuf & B01 B03 B04 B05 B07 B08 B21 B22 B23 B24 B25 B26 B27 B28 B29 B30 B32 B42 B43 B65 \\
& B66 B67, BUT NOT B01D35-53 AND NOT B01J [Manufacture of LEDs/OLEDs/PLEDs \\
& mainly, but with some applications mixed in. Excluding B01D35-53 and B01J rules out \\
FundChem & C07-08 C09C C09K11 C01 C02 C03 C04 C09 C12 C22 C23 C25 C30 \\
Organic & C07 C08
\end{tabular}

copyright (C2009 Kenneth L. Simons, reproduced by permission

Table 5. Title-based categories used in technology category definitions

\begin{tabular}{|c|c|}
\hline Category & Definition (keywords included) \\
\hline DispPrintScan & $\begin{array}{l}\text { display screen panel matrix array pixel printhead "print head" printer scanner } \\
\text { "head" "head" }\end{array}$ \\
\hline Display & display screen panel \\
\hline PrintScan & printhead "print head" print-head printer scanner " head" "head" \\
\hline Indicator & indicator indicating "status led" \\
\hline Backlight & backlight "back light" \\
\hline Lamp & lamp lighting luminaire luminary bulb illuminat leuchsystem lumen luminosity beleuchtung \\
\hline WhiteLight & 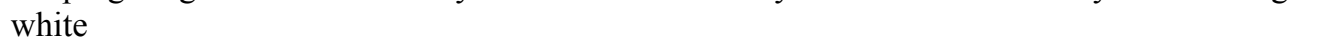 \\
\hline ColorLight & color " red" "red" orange yellow green blue indigo violet purple \\
\hline Vehicle & vehicle vehicular automobile automotive motorcycle motocicl \\
\hline Organic & organic “ oled" “^oled” oleds pled pleds polym monom ligand hydroxy macromol organics \\
\hline MetalOrganic & "metal organic" "metal-organic" metalorganic \\
\hline Packaging & packag encapsula \\
\hline
\end{tabular}

copyright (C2009 Kenneth L. Simons, reproduced by permission

since members of international "patent families" are not double-counted. There are more than twice the number of applications for patents or utility models than there are actual patents or utility models granted. We present some of the main data on applications and utility models in this section and focus most of the discussion in later sections on granted patents, which provide a stronger measure of high quality innovation.

When counting applications for patents or utility models, several considerations arise. Some common mistakes of interpretation are discussed below, to avoid errors when examining data reported herein. International patent families are explained, along with our treatment of them. Counting methods are also explained, including why fractional patent counts often result. 


\subsection{Mistakes of interpretation to avoid}

Several common mistakes should be avoided when examining applications and patents data:

- Decreases in counts in recent years need not indicate a slowdown in patent-related activity. There are substantial (legally imposed) time delays between when an applicant files for a patent or utility model and when details of the application are made public knowledge. Nations also differ in how rapidly they make available information to the EPO for inclusion in online data and in the EPO patent database that is our initial information source.

- Granted patents and utility models here are not reported by grant year but by application year. The focus on application years makes it possible to analyze when R\&D activity occurred, rather than how long it took for a national patent office to approve an application.

- Company-specific counts do not represent all of a company's SSL- or LED-related patents. Typically the data used here seem to capture about $50 \%$ of LED-related applications, and it is possible for this figure to vary by firm.

- Counts are not free of error. Small variations in the counts are likely based on whether or not particular applications happen to be included in the data. If the intent is to measure a company's or nation's underlying R\&D activity, moreover, there are both systematic variations in the propensity for a company's or nation's personnel to choose to file for patents or utility models, and random variations in whether or not a potential application is in fact filed. Random fluctuations are most likely to be important for counts of 10 or fewer, because the changes in apparent R\&D output then tend to be large relative to the total count.

- All patents are not equal. The distribution of monetary gains achieved from patents is well known to be highly skew, with a few patents accounting for the bulk of the value. Therefore the counts used here are useful to gauge the extent of R\&D activity, but not the extent of R\&D success. Attempts to measure the value of patents, or at least whether patents have some minimal threshold value, are sometimes based on citations received or whether renewal fees are paid (in nations where patents must be renewed for a charge), but unfortunately the requisite data are not available for most of the dataset used here. An alternative, the development of international patent families, will be discussed below.

Despite these cautions that must be exercised when interpreting patent-related data, the information reported here provides valuable evidence about who is carrying out SSL-related R\&D activity in what parts of the world.

\subsection{International patent families}

Rights for an invention are often applied for in multiple nations, such that a nearly identical application is translated into each nation's working language and legal documents to seek to obtain patent (or utility model) rights are filed with each nation's patent authority. The set of near-identical applications filed for the same invention with multiple patent authorities is termed an "international patent family." Families are identified by European Patent Office personnel according to two alternative definitions, DocDB and Inpadoc families, and here we use the Inpadoc definition of international patent families. Families may also include more than one application filed in the same nation, because applications may go through a series of legal stages before being ready for potential granting of rights.

Applications from the same international patent family are here counted only once. This avoids double-counting of RD on the same technology. However, it is well known that patents in international families tend to have greater value than patents not in international families. In fact, estimates suggest an average increase in patent value of about $40 \%$ per additional nation. ${ }^{[4]}$ We therefore in some cases report data restricted to applications in international families.

\subsection{Division of credit across applicants and inventors}

A given application may have multiple applicants and inventors, sometimes based in different nations. To avoid doublecounting of R\&D activity, we therefore divide credit equally amongst all inventors and applicants on each applications. This results in fractional counts that more accurately reflect SSL R\&D activity.

\subsection{Applications, grants, and patents}

Applications here denote any filing with a national or regional patent office with the intent to obtain patent rights, utility model rights, or in communist nations, formal recognition such as inventor's certificates. Typically analyses here focus on granted patents. In some cases we analyze all grants, including utility models and (much rarer) inventor's certificates. 
Our total count of applications in the data is 120,728 , with 50,356 grants of which 38,625 are granted patents. Utility models, as noted earlier, are easy-to-obtain variants of patents that last typically six years and are available from some nations' patent authorities (not the U.S.).

\subsection{Frequency of technology sub-domains}

Applications in the database were classified into technology sub-domains as noted in section 2.4. Out of the 120,728 applications in the data, Table 6 indicates how many applications fall within each pair of technology sub-domains. Some sub-domains are exclusive from others. Applications classified in the sub-domain labeled All But Displays, Printing, Scanning never appear in the sub-domain labeled Displays. Likewise, applications classified in Lighting never appear in Fundamentals or Displays. Other sub-domains overlap. Of the 18,908 applications in Lighting, 1,913 are also in Organic and 879 are also in Vehicles. Similar overlaps can be read from the table for other pairs of sub-domains.

Numbers on the diagonal of Table 6 indicate how many applications fall within each sub-domain. The largest subdomain is All Except Displays, Printing, Scanning with 76,513 applications. The second largest sub-domain is Fundamentals with 74,893 applications. The smallest sub-domain considered here is Vehicles, with 2,057 applications.

Since the primary focus here is on granted patents, Table 7 presents similar data on sub-domains restricted to granted patents. Not surprisingly the number of patents is much smaller than the number of applications in each sub-domain. The largest sub-domain among patents is Fundamentals with 25,425 patents, followed closely by All But Displays, Printing, Scanning with 24,304 patents. The smallest sub-domain is Vehicles with only 587 patents included in the dataset.

Table 6. Frequency and cross-categorization of applications by technology sub-domains

\begin{tabular}{|c|c|c|c|c|c|c|}
\hline Sub-Domain & $\begin{array}{l}\text { All except } \\
\text { displays, } \\
\text { printing, } \\
\text { scanning }\end{array}$ & Lighting & Fundamentals & Displays & Organic & Vehicles \\
\hline $\begin{array}{l}\text { All except } \\
\text { displays, printing, } \\
\text { scanning }\end{array}$ & 76,513 & 18,908 & 53,901 & 0 & 9,945 & 1,436 \\
\hline Lighting & 18,908 & 18,908 & 0 & 0 & 1,931 & 879 \\
\hline Fundamentals & 53,901 & 0 & 74,893 & 18,604 & 12,496 & 296 \\
\hline Displays & 0 & 0 & 18,604 & 39,014 & 7,444 & 517 \\
\hline Organic & 9,945 & 1,931 & 12,496 & 7,444 & 17,682 & 23 \\
\hline Vehicles & 1,436 & 879 & 296 & 517 & 23 & 2,057 \\
\hline
\end{tabular}

Table 7. Frequency and cross-categorization of patents by technology sub-domains

\begin{tabular}{lcccccc}
\hline Sub-Domain & $\begin{array}{l}\text { All except } \\
\text { displays, } \\
\text { printing, } \\
\text { scanning }\end{array}$ & Lighting & Fundamentals & Displays & Organic & Vehicles \\
& 24,304 & 5,003 & 18,498 & 0 & 3,449 & 411 \\
\hline $\begin{array}{l}\text { All except } \\
\text { displays, printing, }\end{array}$ & & & & & & \\
scanning & 5,003 & 5,003 & 0 & 0 & 534 & 264 \\
Lighting & 18,498 & 0 & 25,245 & 6,079 & 4,316 & 107 \\
Fundamentals & 0 & 0 & 6,079 & 12,869 & 2,713 & 135 \\
Displays & 3,449 & 534 & 4,316 & 2,713 & 6,244 & 7 \\
Organic & 411 & 264 & 107 & 135 & 7 & 587 \\
Vehicles & & & copyright (2009 Kenneth L. Simons, reproduced by permission
\end{tabular}




\subsection{Activity by patent authority}

Most previous studies of patenting in SSL have focused on patents filed in the United States, potentially overrepresenting the strength of English-speaking nations, particularly the U.S., and under-representing other nations. Boyack et. al. recognized this limitation in their 2006 analysis of international trends in SSL. ${ }^{[1]}$ Focusing on patents applied for and granted in patent authorities around the world, as in our study, is likely to lead to a better understanding of knowledge creation worldwide.

About four times as many LED-related patent applications have been filed with the Japan Patent Office (JPO) compared to the next highest number filed with the U.S. Patent and Trademark Office (USPTO). Reliance on USPTO data alone would ignore the large number of applications applied for in Japan, many filed for by Japanese companies. When patents rather than applications are used as the measure, the apparent gap between the U.S. and Japan is much smaller, with only about $10-20 \%$ more patents granted in Japan than in the U.S.. In fact this comparison is for many purposes more accurate. Japanese patent law before 2001 gave companies seven years from filing before they had to decide whether to pay for a full evaluation, whereas after 2001 the maximum time lag was shortened to three years. In other ways as well, the Japanese patent system has moved closer to the U.S. patent system over time. ${ }^{[2],[3],[5]}$ Focusing on patents rather than applications helps to make counts more comparable between the two nations in all years. An alternative also used below is to consider only applications filed in multiple nations.

We looked further into the issue of whether multi-national patent data are needed to achieve unbiased counts, by analyzing the nation-specific makeup of the patent portfolios of LED companies in Japan. For example, we compared data on Nichia's semiconductor patents received from the JPO to those received from the USPTO and other patent authorities around the world. Nichia has three times the number of granted patents in Japan compared to the U.S., judging from their public list of semiconductor patents. If Nichia is typical of other non U.S. headquartered firms - as turns out to be the case - considering only USPTO patents would undercount the intellectual property of firms not headquartered in the U.S. and potentially result in a nation-specific bias. While it is sometimes argued that the U.S. market is sufficiently large that it should attract patent filings for all valuable technologies worldwide, it is curious that in fact many firms doing serious R\&D choose to file for patents primarily in their home nations. There are several potential reasons for this home-nation tendency, such as using patents as a means to show activity rather than to gain rights or using patent rights primarily as competitive tools against firms also active in the same nation which are perhaps most likely to sell similar products in related geographic markets. Whatever the reasons, the evidence suggests that to avoid potentially serious nation-specific biases, data from patent authorities worldwide are needed.

\section{SELECTED FINDINGS ON COMPANIES}

Figure 1 shows the performance of firms for the two half-decades 1999-2003 and 2004-2008. Over the first half decade, Seiko led, with Philips, SEL, Sharp, Sanyo, Matsushita, and Siemens close behind. Samsung and Kodak have almost the same number of granted patents, followed closely by Nichia and Toshiba. Other Japanese firms, and Taiwanese and U.S.-headquartered firms, trailed.

In the subsequent period beginning in 2004, the number of patents granted to Samsung grew very quickly, exceeding all other firms almost four times over. Matsushita, Philips, Kodak, Seiko, Sharp, and Siemens were consistently strong in these time periods. LG and AU Optronics made large strides from 1999 to 2004 receiving some of the largest numbers of patents. During 2004-2008 some new players have begun to have significant LED patents, including Korea's Seoul Opto Device and Seoul Semiconductor, Taiwan's ITRI and Formosa Epitaxy, and in the U.S., Kodak, 3M, GE, and Cree.

Instead of patents, two alternative metrics could be used. One is applications, which captures the most recent activity of companies before patents have time to be granted. When this is used as the metric, Samsung again stands out as the dominant firm in the most recent five-year period. The other, used in Figure 2, is applications filed in multiple nations, which restricts the analysis to applications of relatively high quality as discussed in section 3.2 (while still retaining a reasonable sample size by using applications rather than granted patents). By this measure, Philips has been very strong in R\&D especially in the period 1999-2003. SEL, Seiko, Samsung, and Siemens, respectively, closely trailed Philips' application counts during this period. Siemens and a number of Japanese firms interrupted only by Kodak follow. Agilent and GE appear near the end of the list. 
1999-2003

$0 \quad 125250375 \quad 500$

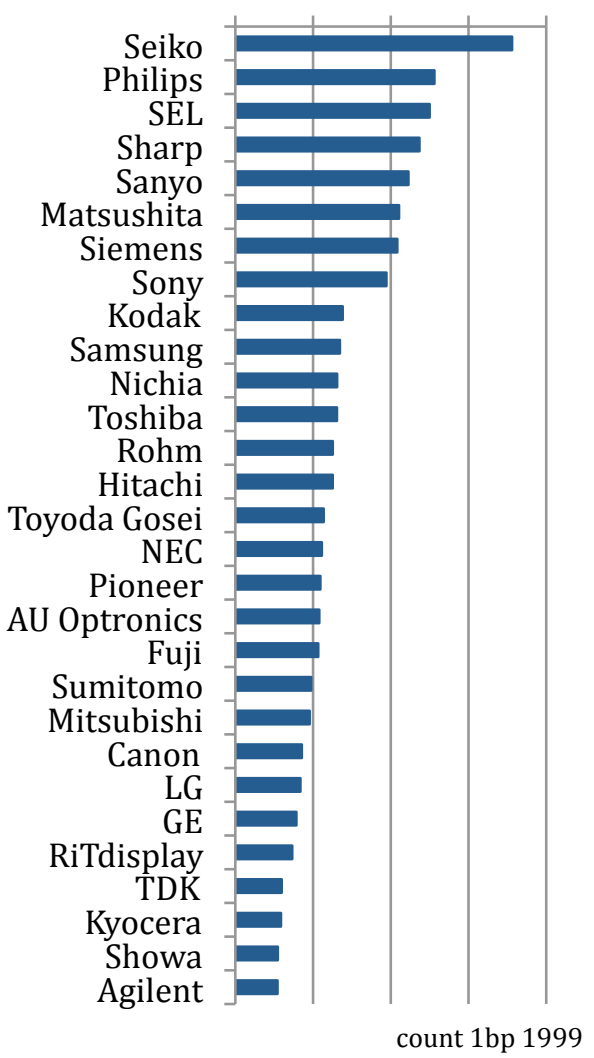

2004-2008

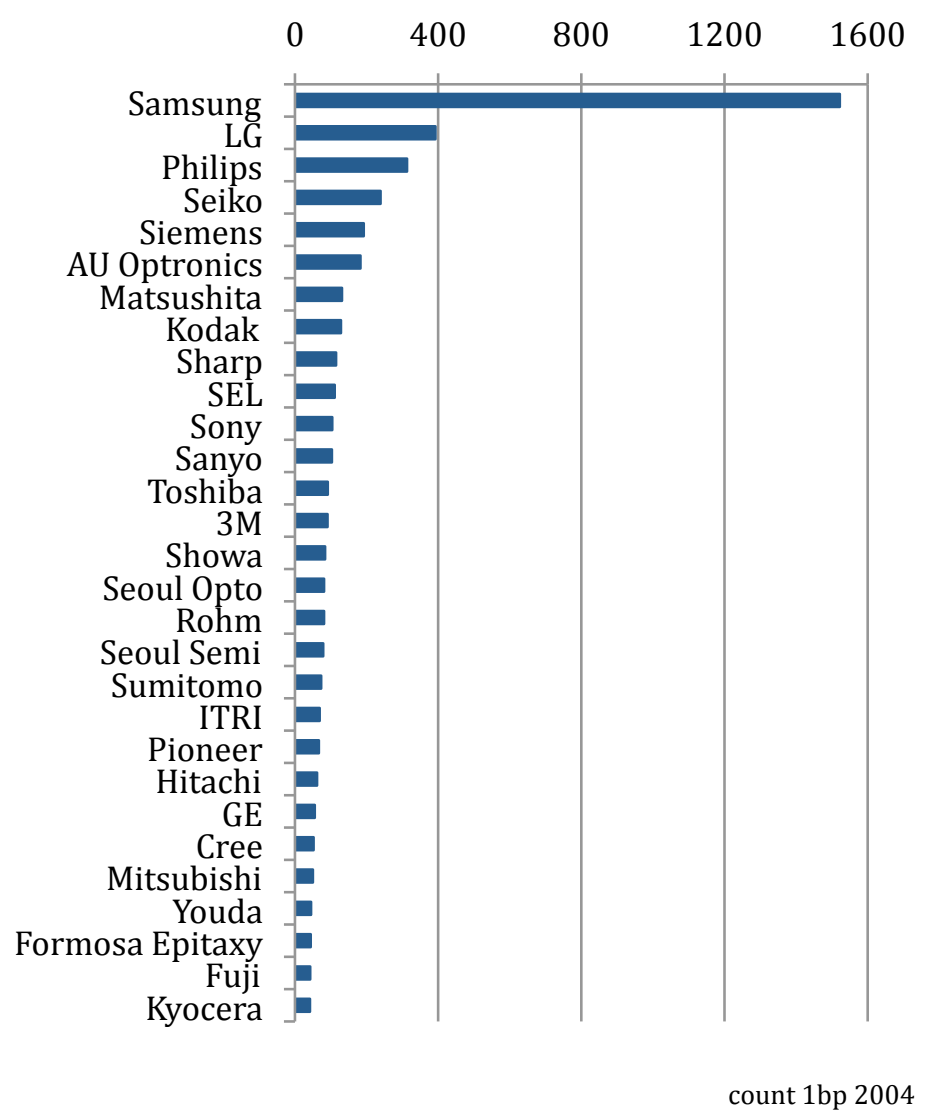

Figure 1. All LED patents granted to top firms filed in 1999-2003 and 2004-2008 (copyright (C2009 Kenneth L. Simons, reproduced by permission)

In the most recent half-decade beginning in 2004, Samsung emerges definitively as the R\&D leader by this apparent high-quality measure, far above Philips, its nearest competitor in patent applications in multiple nations. Siemens and the same strong Japanese companies from the earlier period again lead in having apparently high-quality patents, with moderately strong activity apparent in a few U.S. firms, Kodak, Cree, Agilent, and 3M.

When analysis is focused on a particular technology sub-domain, the conclusions are somewhat different depending on the category considered. After ruling out applications related to displays, printers, and scanners, the top-ranked companies for 1999-2003 by patents granted were (in order) Siemens, Matsushita, Sharp, Philips, Toyoda Gosei, Nichia, Toshiba, and Sumitomo; or, using multi-national applications, Siemens, Philips, Toyoda Gosei, Sharp, Matsushita, Samsung, Sony, and Kodak. In 2004-2008, the top-ranked companies by (the limited number of) patents granted to date were Samsung, LG, Philips, Siemens, Matsushita, Showa, Seoul Opto., and Seoul Semi, 3M, and Seko; or, using multinational applications, Samsung, Philips, Siemens, LG, Seko, Sharp, SEL, and Toshiba. American firms Cree, Kodak, GE, Avago Technologies, Agilent, and 3M also are among the leading companies, but farther down the list, when ranked by multi-national applications in 2004-2008.

Focusing on the very narrowly defined Lighting sub-domain, defined earlier to have a somewhat applied lighting focus, the big traditional lighting firms appear to have had leading roles particularly during 1999-2003 and still somewhat during 2004-2008. All patents classified as involving fundamental technologies of LEDs, materials, and circuitry are excluded, as well as patents related to displays, printers, scanners, indicator lights (based on title keywords), and some other topics. Figure 3 shows patenting activity by firm in the resulting narrow set of patents. Although some of the leading firms continue to be traditional lighting firms, Samsung and LG have made important inroads into this category 
1999-2003

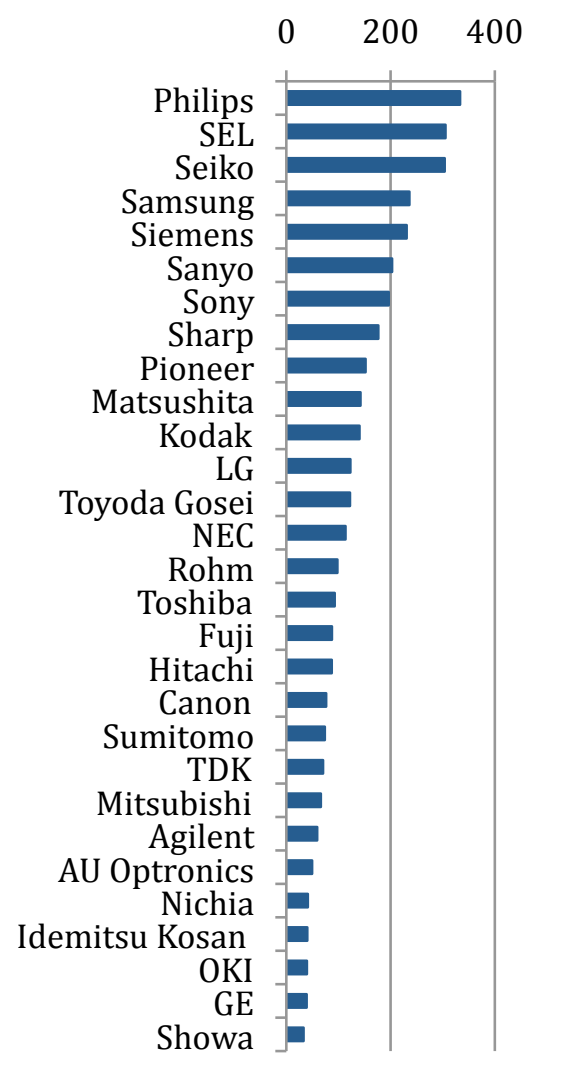

2004-2008

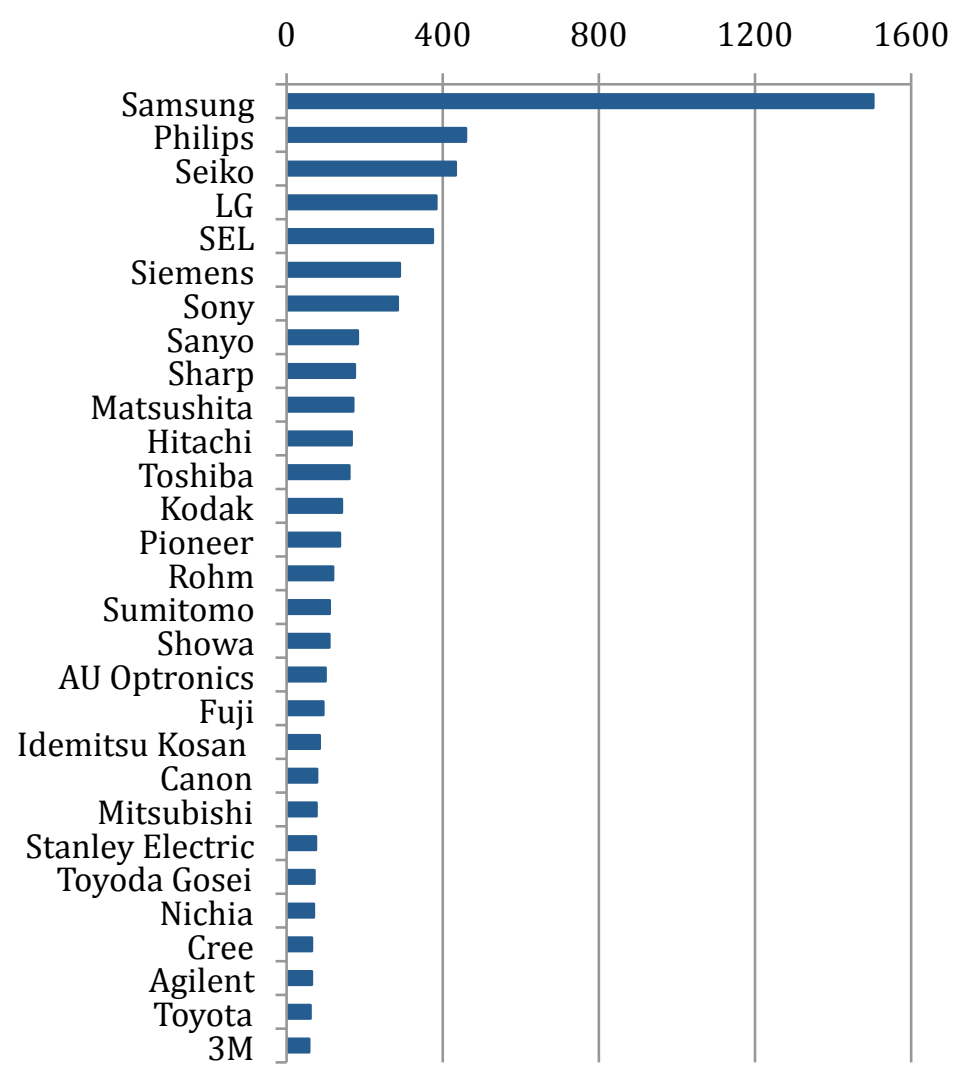

count 1na 2004

Figure 2. All LED multi-nation applications of top firms filed in 1999-2003, 2004-2008 (copyright (C2009 Kenneth L. Simons, reproduced by permission)

during 2002-2008. We have not yet fully investigated this phenomenon and the extent to which it is real versus, possibly, a quirk of our technology categorization.

For patents related to fundamental technologies, Samsung has had about three times the number of granted patents, and almost four times the number of multi-national applications, as any other firm during application years 2004-2008. LG, Philips, Seiko, Siemens, Sharp, Matsushita, and Kodak have the next-highest rankings and are not enormously different from each other in terms of counts.

For patents related to displays, Samsung has led by more than a factor of four during the same time period, trailed by Seiko, LG, AU Optronics, and other companies. Samsung still leads this enormously when multi-national applications are considered, but SEL (second place) and Sony (fourth place) also rank very highly.

For patents related to organic LEDs, Samsung has even greater dominance of the number of patents granted so far from applications filed in 2004-2008, with LG, AU Optronics, and Kodak being the distant followers. AU Optronics ranks somewhat lower (seventh) when multi-national applications are used as the measure.

For patents or applications related to vehicles, the numbers of patents and applications involved have been much lower and it would be relatively dangerous to try to rate the leading firms. Some of the leaders appear to be Koito Manufacturing, Siemens, Denso, Hella, Valeo, and Toyoda Gosei.

For the top 10 companies in terms of All LED patents granted in all years, Table 8 shows the most common twelve patent authorities in which their applications were granted. The left column of the table lists the companies in order of 

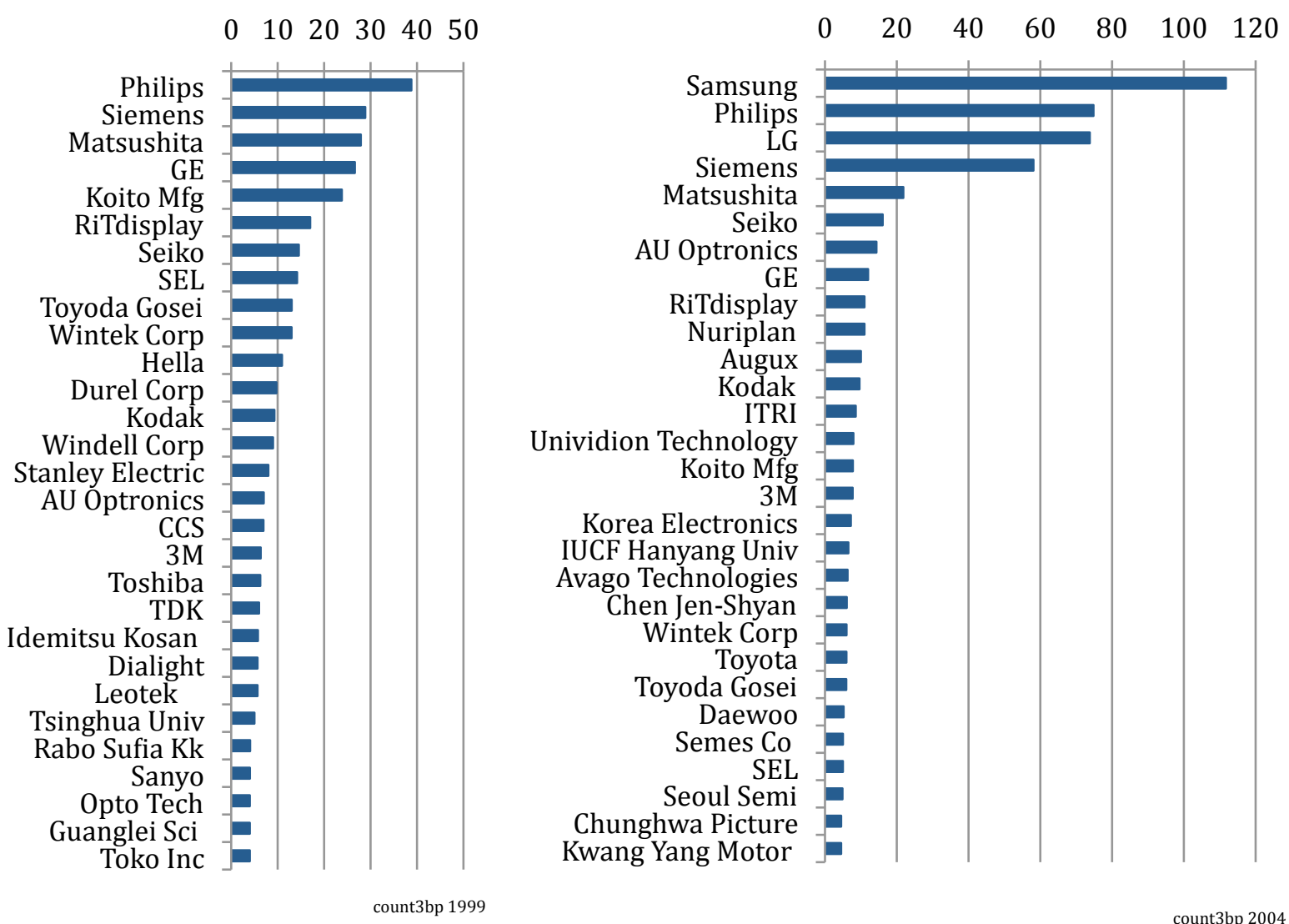

Figure 3. Lighting patents granted to top firms for 1999-2003 and 2004-2008 (copyright (C2009 Kenneth L. Simons, reproduced by permission)

Table 8. Leading companies' patents granted by patent authority

\begin{tabular}{lllllllllllll}
\hline & \multicolumn{10}{c}{ Number of patents by authority in which patents were granted } \\
Company & JP & US & TW & CN & KR & EP & GB & DE & FR & IB & CA & IT \\
\hline Samsung & 110 & 385 & 30 & 211 & 1324 & 27 & 14 & 31 & 5 & 0 & 1 & 0 \\
Sharp & 1028 & 451 & 95 & 97 & 14 & 74 & 48 & 59 & 8 & 0 & 3 & 0 \\
Matsushita & 915 & 381 & 82 & 80 & 6 & 54 & 61 & 38 & 47 & 7 & 14 & 5 \\
Philips & 70 & 641 & 132 & 120 & 17 & 229 & 128 & 68 & 178 & 355 & 35 & 38 \\
Siemens & 60 & 555 & 173 & 96 & 2 & 181 & 100 & 327 & 69 & 1 & 11 & 13 \\
Seiko & 595 & 305 & 300 & 258 & 6 & 62 & 15 & 0 & 0 & 0 & 1 & 0 \\
Toshiba & 629 & 357 & 85 & 59 & 41 & 45 & 34 & 13 & 8 & 0 & 8 & 7 \\
NEC & 676 & 147 & 44 & 31 & 9 & 53 & 13 & 7 & 3 & 0 & 11 & 0 \\
Sanyo & 449 & 223 & 159 & 106 & 2 & 12 & 0 & 2 & 0 & 0 & 2 & 0 \\
Mitsubishi & 414 & 333 & 28 & 33 & 13 & 44 & 27 & 25 & 18 & 0 & 9 & 0 \\
\hline
\end{tabular}

Note: $\mathrm{JP}=$ Japan, US=United States, $\mathrm{TW}=$ Taiwan, $\mathrm{CN}=\mathrm{China}, \mathrm{KR}=$ Korea, $\mathrm{EP}=$ European Patent Office, GB=Great Britain, $\mathrm{DE}=$ Germany, $\mathrm{FR}=$ France, $\mathrm{IB}=$ International Bureau of the World Intellectual Property Office, $\mathrm{CA}=\mathrm{Canada}, \mathrm{IT}=\mathrm{Italy}$.

Copyright C2009 Kenneth L. Simons, reproduced by permission. 
number of patents received. The top of the table lists the patent authority under which an application was filed. Each patent authority is denoted by a two-letter code, listed at the end of the table. Numbers in the table indicate the number of patents granted to each company in each of the twelve leading patent authorities. For example, Samsung received 110 patents in Japan, 385 in the United States, 30 in Taiwan, 211 in China, 1,324 in Korea, 27 at the European Patent Office, 14 in Great Britain, 31 in Germany, 5 in France, none at the International Bureau of the World Intellectual Property Office, 1 in Canada, and none in Italy. Inspection of the table quickly makes apparent that firms tend to file for patent rights in their home nations. There is a tendency to file for patent rights in the U.S., which has been the world's largest consuming economy, more often than in other nations. Nonetheless, apparently there are ample motivations for companies to file for rights elsewhere as well.

\section{SELECTED FINDINGS ON NATIONS}

The nations in which strong LED-related R\&D is occurring might be considered in two alternative ways: by company headquarters nation or by the nation in which invention occurs (specifically, the nation of residence of each inventor circa the date of filing). The results are similar either way, and the focus here is on the nation of invention.

Figure 4 shows counts by time period mined for granted patents filed in 1999-2003 or in 2004-2008. The traditional dominance of Japan as an early developer of LEDs is apparent in both periods. However, the effect of Samsung's recent activity is apparent in the rapid growth of Korean patent counts in the latter period. The counts for Taiwan and China are higher than one might have guessed based or companies' activity, because large numbers of independent inventors and small firms have been filing for patent rights in both countries. Moreover, in both countries firms and individuals have been filing for large numbers of utility models, which are not considered in the counts of granted patents. This apparently reflects the manufacturing orientation of activity in the two nations, especially China. Similar patterns to those in Figure 4 are apparent when applications or multi-nation applications are considered. These metrics, however, suggest a substantially greater lead by Japanese inventors, with almost twice as many applications as those filed by Korean inventors even during 2004-2008.

1999-2003

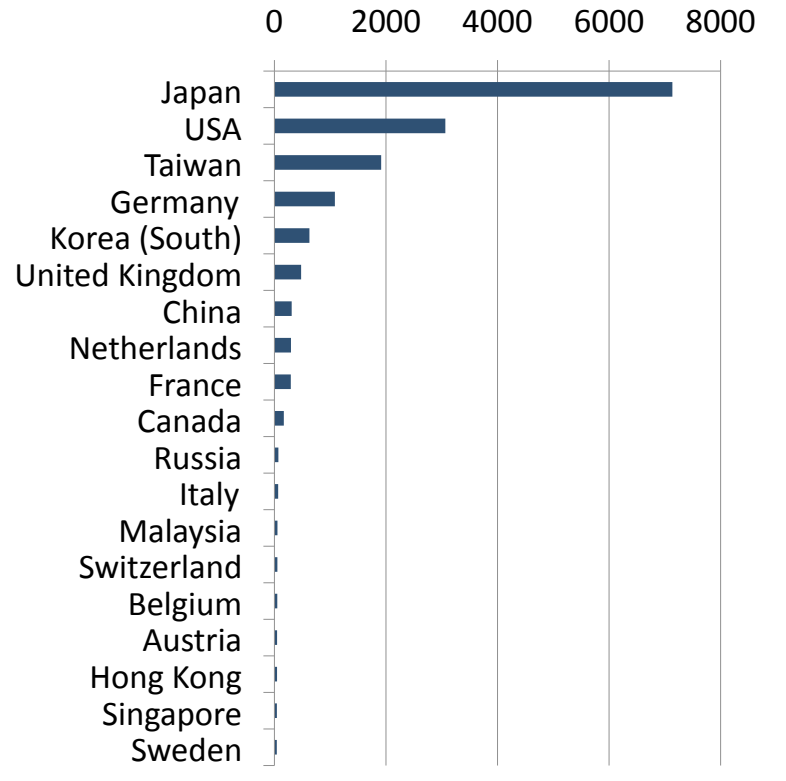

count1bp 1999
2004-2008

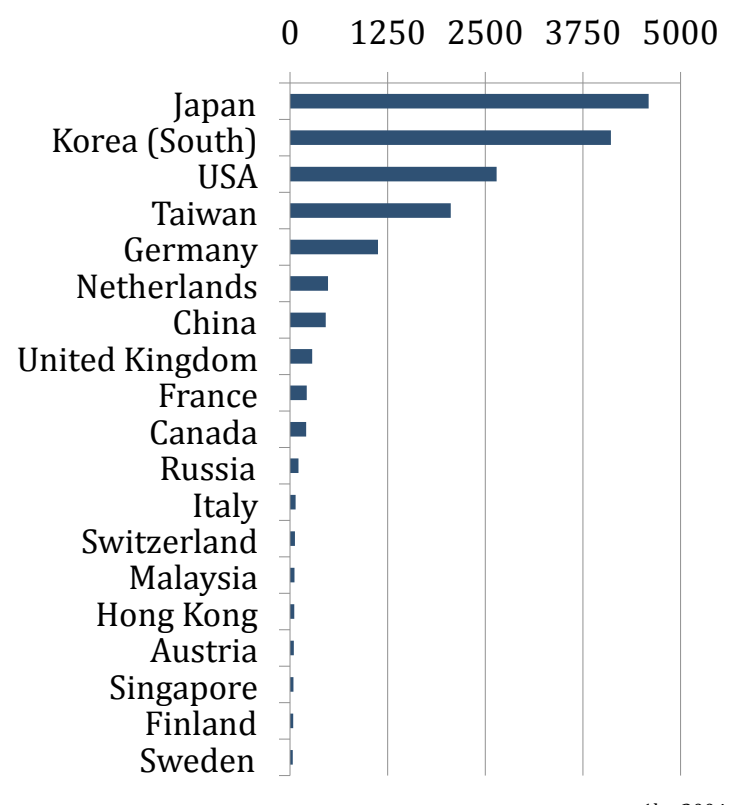

count1bp 2004

Figure 4. All LED patents granted to top inventors for 1999-2003 and 2004-2008, nations of invention (copyright (C2009 Kenneth L. Simons, reproduced by permission) 
Table 9. U.S. applicants with greatest number of applications

\begin{tabular}{|c|c|c|c|c|c|c|c|c|c|c|}
\hline Firm & HQ & $\begin{array}{l}\text { Apps. } \\
\text { All }\end{array}$ & $\begin{array}{l}\text { Grants } \\
\text { All }\end{array}$ & All & Except & Light. & $\begin{array}{c}\text { Patents } \\
\text { Fund. }\end{array}$ & Displ. & Organ. & Veh. \\
\hline Kodak & US & 656.5 & 435.7 & 435.7 & 207.8 & 20.9 & 315.7 & 184.9 & 263.4 & 0.0 \\
\hline GE & US & 374.0 & 318.0 & 305.8 & 258.7 & 114.7 & 161.1 & 43.7 & 30.7 & 0.6 \\
\hline IBM & US & 233.7 & 204.2 & 204.2 & 125.2 & 12.1 & 163.9 & 77.5 & 27.5 & 1.0 \\
\hline Motorola & US & 217.5 & 192.7 & 192.7 & 92.6 & 7.7 & 146.5 & 97.1 & 37.0 & 0.0 \\
\hline Westinghouse & US & 209.4 & 191.0 & 191.0 & 143.4 & 118.4 & 37.7 & 41.6 & 1.3 & 2.6 \\
\hline Agilent & US & 180.4 & 92.3 & 92.3 & 60.6 & 3.5 & 79.3 & 28.9 & 11.8 & 1.5 \\
\hline HP & US & 174.2 & 125.3 & 124.1 & 70.1 & 3.6 & 82.7 & 35.7 & 5.5 & 0.0 \\
\hline $3 \mathrm{M}$ & US & 173.9 & 157.0 & 157.0 & 109.3 & 17.7 & 127.6 & 24.9 & 28.7 & 2.0 \\
\hline Cree & US & 147.5 & 100.1 & 90.1 & 80.8 & 5.1 & 80.5 & 8.6 & 0.8 & 0.0 \\
\hline
\end{tabular}

Table 9 lists U.S. companies with the greatest numbers of applications to date in the data, along with their numbers of applications, granted patents and utility models, and granted patents overall and by technology sub-domain. The list includes both presently and previously active firms, and provides a brief overview of a few of the key U.S. players.

\section{ACKNOWLEDGMENTS}

Research assistance was provided by Woojoon Choi, Phillip Harris, Inbeom Paul Kwon, Yin-Yi Lai, Young Lee, William Maio, Liliana Martinez, Alex Palkovic, Anthony Parke, Cong Pu, Guo Qin, Daniel Rubio, Jeremy Schuh, Yuanjiao Shen, Mike Shen, Rongwei Yu, Steve Valiquette, Nathan Whalen, Xu Zhang, and Shan Zhong. We thank Ed Petrow, Jim Brodrick, Wu Ling, Bing Liang, Ming Zhu, Fred Schubert and other members of the Smart Lighting Engineering Research Center, and participants in seminars at the U.S. Department of Energy (D.O.E.) and the February 2009 D.O.E. Solid State Lighting Workshop for helpful comments and discussion.

This material is based upon work supported by the U.S. Department of Energy through their Efficiency and Renewable Energy (EERE) Programmatic Lighting Support program, award 570.01.05.007, "SSL Global Technology Analysis;" by the National Science Foundation under Cooperative Agreement EEC-0812056, through its Smart Lighting Engineering Research Center; and by undergraduate research funds provided by Rensselaer Polytechnic Institute. Neither the United States Government nor any agency thereof, nor any of their employees, makes any warranty, express or implied, or assumes any legal liability or responsibility for the accuracy, completeness, or usefulness of any information, apparatus, product, or process disclosed, or represents that its use would not infringe privately owned rights. Reference herein to any specific commercial product, process, or service by trade name, trademark, manufacturer, or otherwise does not necessarily constitute or imply its endorsement, recommendation, or favoring by the United States Government or any agency thereof. The views and opinions of authors expressed herein do not necessarily state or reflect those of the United States Government or any agency thereof. In particular, any opinions, findings, and conclusions or recommendations expressed in this material are those of the authors and do not necessarily reflect the views of the National Science Foundation. Nor do any such opinions, findings, conclusions, or recommendations necessarily reflect the views of Rensselaer Polytechnic Institute or of the Smart Lighting Engineering Research Center.

\section{REFERENCES}

[1] Boyack, K. W., Tsao, J. Y., Miksovic , A. and Huey, M., "International trends in solid state lighting: analyses of the article and patent literature," manuscript (2006).

[2] Goto, A. and Motohashi, K., "Construction of a Japanese patent database and a first look at Japanese patenting activities," Research Policy, 36, 1431-1442 (2007).

[3] Kotabe, M., “A comparative study of U.S. and Japanese patent systems," Journal of International Business Studies, 23(1), 147-168 (1992).

[4] Lanjouw, J. O., Pakes, A. and Putnam, J., "How to count patents and value intellectual property: the uses of patent renewal and application data," Journal of Industrial Economics, 46(4), 405-432 (1998).

[5] Motohashi, K., “Japan's patent system and business innovation: reassessing pro-patent policies,” RIETI Discussion Paper 03-E-020 (2003). 